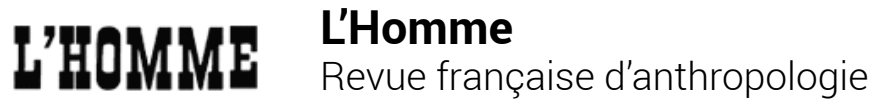

Oralité et écriture

\section{Réda Benkirane \& Erica Deuber Ziegler, eds, Culture et cultures. Les chantiers de l'ethno}

\author{
Nicolas Adell-Gombert
}

\section{(2) OpenEdition \\ 1 Journals}

\section{Édition électronique}

URL : http://journals.openedition.org/lhomme/28776

DOI : 10.4000/lhomme.28776

ISSN : 1953-8103

Éditeur

Éditions de l'EHESS

\section{Édition imprimée}

Date de publication : 1 janvier 2009

Pagination : 278-279

ISSN : 0439-4216

\section{Référence électronique}

Nicolas Adell-Gombert, « Réda Benkirane \& Erica Deuber Ziegler, eds, Culture et cultures. Les chantiers de l'ethno ", L'Homme [En ligne], 189 | 2009, mis en ligne le 03 janvier 2017, consulté le 24 septembre 2020. URL : http://journals.openedition.org/lhomme/28776 ; DOI : https://doi.org/10.4000//homme. 28776

Ce document a été généré automatiquement le 24 septembre 2020.

(c) École des hautes études en sciences sociales 


\title{
Réda Benkirane \& Erica Deuber Ziegler, eds, Culture et cultures. Les chantiers de l'ethno
}

\author{
Nicolas Adell-Gombert
}

\section{RÉFÉRENCE}

Réda BenkiRAne \& Erica Deuber ZiegleR, eds, Culture et cultures. Les chantiers de l'ethno. Avant-propos d'Edgar Morin, Genève, Musée d'ethnographie de Genève, 2007, 345 p., bibl. (« Tabou »).

1 SOUS UN TITRE anodin, cet ouvrage recèle un sujet d'une brûlante actualité : «À quelle culture contribue un musée d'ethnographie en parlant [des] différentes cultures?» (p. 11). L'objet, on le sait, est polémique. Il l'est d'autant plus ici que, réunis lors d'un colloque organisé par le Musée d'ethnographie de Genève en 2001, les auteurs ont souffert de l'échec du projet muséal suisse de « l'Esplanade des mondes » tandis que son pendant parisien, le musée du quai Branly, se finalisait. Ils semblent en avoir, pour la plupart, nourri un vif ressentiment. Ce sera donc un livre de combat ou, si l'on veut, de résistance.

2 Il en a les qualités et les défauts. On y lit de la passion, la volonté d'explorer une muséographie expérimentale pour radicaliser encore l'opposition à l'institution parisienne jugée passéiste. La démonstration par opposition irrigue une large partie des communications : «musée d'art » contre "musée de travail » (p. 12) ou de "société » (p. 164); «musée d'objets » contre «musée d'idées» (p. 149). Au fond, et bien que les responsables s'en défendent (p.91), c'est la lutte fondamentale de l'esthétique et de la science qui est ici mise en scène.

3 L'ouvrage est ordonné selon trois axes alimentés de manière hétérogène par quinze contributions de valeur inégale. 
4 Le premier constitue le pôle théorique destiné à travailler la notion de culture avec les textes de Pierre Centlivres, Louis Necker (ancien directeur du MEG), Réda Benkirane et Erica Deuber Ziegler, José Marin. La communication de Pierre Centlivres résume de manière classique la dynamique de l'opposition lexicale culture/civilisation à partir de la présentation des traditions ethnologiques française et allemande jusqu'au milieu du $\mathrm{xx}^{\mathrm{e}}$ siècle. Il rappelle la victoire $\mathrm{du}$ terme «culture " après la relecture opérée par Claude Lévi-Strauss dans les années 1950, mais insiste sur le fait qu'elle reste aujourd'hui un outil dangereux, susceptible d'«essentialiser les différences » (p. 59), mais néanmoins «irremplaçable» (ibid.). Le texte des responsables de l'ouvrage prolonge la réflexion en l'orientant sur la question, intéressante mais traitée de manière superficielle, des objets-témoins. L'intervention de José Marin clôture de façon sommaire ce premier volet en faisant un résumé de "l'occidentalisation du monde » depuis les croisades (p.97) jusqu'au phénomène du clonage (p.117). Seule l'intervention de Louis Necker permet, dans un premier temps, de porter le débat à un autre niveau en évoquant d'abord l'héritage colonial de la notion de culture (p. 67) et le problème que cela pose vis-à-vis des musées d'ethnographie, institutions de la culture, avant d'inviter, page 69, à une approche dynamique de la muséographie (telle qu'elle se pratique en Suisse notamment) qui fait interagir "Nous» (les muséographes), l'« Autre » (l'objet) et « Eux» (le public).

5 Le deuxième chantier convie justement différentes personnalités à réfléchir sur les pratiques muséographiques. On est au cœur de la polémique, là où les prises de position sont les plus radicales, en particulier dans les premiers textes, ceux de Jacques Hainard, Bernard Dupaigne et Laurent Aubert. Jacques Hainard, qui a pris la direction du MEG après de longues années passées à Neuchâtel à développer une muséographie d'avantgarde, mène une critique bien argumentée à l'encontre du quai Branly et du pavillon des Sessions du Louvre, insistant sur la nécessité de «rejouer l'objet» (p. 125), de renoncer à en faire des témoins (de quoi témoignent-ils réellement?), perspectives trop peu engagées, selon lui, dans les institutions parisiennes. Au quai Branly, l'absence de l'Europe et des «grandes» civilisations asiatiques (qui restent au musée Guimet) sont dénoncées sinon comme les restes d'anciennes hiérarchies culturelles, en tout cas comme instaurant de fait une démarcation entre "Eux» et "Nous $»^{1}$. Bernard Dupaigne et Laurent Aubert rejoignent leur confrère sur l'essentiel, avec plus de virulence cependant, tout en restant, à mon goût, moins convaincants.

6 Les approches suivantes, excepté le témoignage d'un marchand d'art, rassemblent des réflexions sur des aspects précis de la pratique muséographique : la question de l'usage des nouvelles technologies dans la collecte et l'exposition des objets (Majan Garlinski) ou celle des niveaux de lecture de l'objet ethnographique qui sont le produit de conjonctures historiques (voir l'article de Roberta Colombo Dougoud sur les storyboards du haut Sepik). Jean Davallon développe une réflexion tout à fait pertinente sur la question de la «fonction de communication » du musée qui doit «mettre en relation » (p. 231) non seulement le public et les objets, mais également les visiteurs entre eux par l'intermédiaire des objets. Cet aspect prend une autre dimension lorsqu'il s'agit d'«objets de patrimoine» où s'engagent des enjeux de légitimité et/ou d'identité (pp. 236-240).

7 C'est précisément sur ce point que portent les communications du dernier chantier qui questionne le rôle du musée d'ethnographie dans des sociétés pluri- culturelles à partir d'études de cas précises. Henri Dorion ne nous cèle rien de la diversité des logiques des 
forces en présence en nous exposant le cas paradigmatique des musées canadiens. La "culture " y croise nécessairement, et souvent de manière délicate, la nation, le territoire, la société. Cette dimension éminemment politique, avec laquelle le musée doit composer, peut aussi être pleinement assumée par ce dernier. C'est ce que nous expliquent, de manière différente, Sylvie Dufresne et Jean Guibal. Tandis que la première retrace le rôle joué par le Musée d'archéologie et d'histoire de Montréal dans "l'invention" de la commémoration de la Grande Paix de 1701, signée entre les Français et une trentaine de nations indigènes, le second insiste sur la nécessité de l'ouverture et du comparatisme pour les musées de patrimoine régional, constamment tentés par le repli identitaire et dont la réussite tient précisément dans le fait de mettre en scène les différentes identités à l'œuvre dans la région. L'auteur, sans négliger les limites de tout projet de ce type, nous présente les solutions adoptées au Musée dauphinois depuis les années 1970.

Pour conclure, Erica Deuber Ziegler nous invite à penser le musée comme un « espace interstitiel » (p. 322), lieu de rencontre entre les individus et les cultures et qui doit s'attacher à " préserver la dignité » (p. 325) de chacun et de chacune. L'on ne peut que se joindre à cet élan humaniste tout en regrettant que, assourdis par leur propre appel, les responsables ne nous aient pas fait entendre d'autres voix pour rendre au débat une allure plus contradictoire.

\section{NOTES}

1. Cette critique est également formulée dans Benoît de l'Estoile, «L'oubli de l'héritage colonial », Le Débat, 2007, 147: 91-99.

\section{AUTEURS}

\section{NICOLAS ADELL-GOMBERT}

Université Le Mirail Toulouse-II, LISST-Centre d'anthropologie sociale, Toulouse.

nicolasadell@yahoo.fr 